\title{
On the Analysis of Youth Slang as one of the Subsystems of Modern Russian and English Languages
}

\author{
Svetlana Sheshukova ${ }^{1, *}$, Svetlana Lapitskaja ${ }^{1}$, and Elena Proudchenko ${ }^{1}$ \\ ${ }^{1}$ FSAEI HE Industrial University of Tyumen, Department of Intercultural Communication, 625000, Tyumen, Russia
}

\begin{abstract}
Slang is an essential element of culture. Learning a foreign language is inextricably linked with the study of the culture of native speakers. Teaching slang, idiomatic expressions and phrasal verbs in foreign language classes contributes to the students' vocabulary, understanding informal speech patterns found in media texts and everyday communication with native speakers, developing speaking and listening skills. As a rule, at a foreign language class, students improve their listening, reading, speaking and writing skills through various study materials. Even with these skills, you can fail to communicate with native speakers, read magazines, watch television programmes and travel to foreign countries. The paper discusses the possibility of teaching slang, idiomatic expressions and phrasal verbs in a foreign language class at a technical university. To substantiate the need to study slang, idiomatic expressions and phrasal verbs, the authors attempted to find out how the youth slang is formed and the reasons for its functioning. Youth slang in modern Russian and English languages has been compared and analyzed.
\end{abstract}

\section{Introduction}

To study slang at foreign language lessons is of great interest both for the teacher and for students. The practical value of learning slang is essential for university students as the knowledge of such vocabulary is highly important for successful translation activities [1]. However, learning slang is not suitable for all groups of students. The Federal State Educational Standard (FSES) does not provide slang training in the academic programmes in foreign languages for various courses and profiles of a technical university.

Moreover, if "urban students" [2] do not use slang in everyday communication or if a group of students has a sufficiently low level of language knowledge, studying this group of vocabulary should not be the focus of attention. However, if students are highly motivated to learn a foreign language, communicate with native speakers, travel around the world, then studying some of the most common slang words and idiomatic expressions is definitely necessary.

Since 1997 The Industrial University of Tyumen has been implementing an educational program of supplementary qualification "Translator in the field of professional interaction". This program includes the study of the English language for Intermediate, Upperintermediate and FCE levels. English language teaching and learning resources for teaching English developed by Oxford University Press are used to teach a practical English language course including a teacher's book, a student's textbook, a student's workbook, audio CDs to develop listening, speaking and pronunciation skills. Although this course does not involve learning slang (except songs), the teacher can be creative in planning the lesson by using slang. A variety of themes are of interest to students, developing their knowledge, critical and creative thinking. Besides that, students develop the monologic and dialogical skills. Students practice their skills individually, in pairs, in a group, in a team. Learning slang also helps students educate their native language. Therefore, the study of slang should be built on the principle of comparative analysis of slang words of the Russian and English languages. This is due to the following reasons:

1) In most cases slang vocabulary is adopted from the English language, especially words used in the computer sphere, the Internet, etc.

2) Slang... is changeable and dependent on the era [3] and is the most dynamic segment of both languages, it is constantly being enriched and renewed; 3) Many slang words have both negative and positive connotations which may differ from one language to another.

\section{Purpose of research}

The purpose of the research is to carry out a comparative analysis of the youth slang as one of the subsystems of the modern Russian and English languages, to determine slang as a special expressive meaning of vocabulary, to explain the reasons and its functioning features. In addition, the ways and means of youth slang formation are considered. The choice of the research topic is conditioned by the wide use of slang by Russian and English-speaking youth and the opportunity to introduce the study of slang and idiomatic expressions in the

\footnotetext{
*Corresponding author: helenprud@yandex.ru
} 
educational program of supplementary qualification "Translator in the field of professional interaction".

\subsection{Methods of research}

Slang is an important element of any language and culture and when students reach a certain level of language training, it is necessary to pay attention to this "less academic" form of English. Along with teaching slang, it is advisable to pay attention to idiomatic expressions and phrasal verbs. In our opinion, the most effective ways of learning slang and idiomatic expressions in foreign language classes are:

1) Listening: students need to learn to hear slang words and expressions used in different contexts. It is very important for students to hear and analyze slang words used by native speakers. Moreover, it is also important for students to listen to dialogues with spontaneous rhythm and speed and understand by ear how certain slang words are used. Depending on the topic of the lesson, you can work with audio recordings related to the appearance, studying at the University, household conversations, travel, etc.

2) Videos and clips from TV series are a very effective way to learn slang. The teacher can use a whole episode of a popular TV show or focus on individual scenes from movies or popular TV series. When watching a video or listening to a dialogue, students should pay attention to other details, such as body language or intonation. This will help to better understand the verbal context, slang words and idiomatic expressions.

3) Role play: when students learn a certain number of words and slang expressions, they can be used in some role-playing games. For example, students can write a few words on the board and suggest a role-playing game scenario where they want to use these words or only one word depending on the situation. For example, buying a computer, visiting a doctor, going to a cafe, etc.

4) Written tasks can be diverse. The difficulty of written exercises depends on the language level of the group. For example, for Intermediate/Upper Intermediate level groups the teacher can give the following types of written exercises: fill in the gaps in the text (dialogue) with slang words (idiomatic expressions); replace by phrasal verbs; select a slang word from the synonyms, etc. For more advanced learners (First Certificate English) the following types of written tasks can be offered: read the text (dialogue) and convert it with slang words and expressions. Or vice versa, students are offered a text (dialogue) containing a significant number of idiomatic or slang expressions that need to be converted into a more academic form. When doing these exercises, students learn to switch from one register to another, replenish the active vocabulary, memorize slang words and expressions which they can later use in specific situations of communication. To justify the need to study slang or idiomatic expressions, the authors tried to find out the ways of youth slang formation and the reasons for its functioning. According to I. V. Arnold, slang is the most extensively studied area and one of the "most controversial segments of the language" [4].
Among the various reasons for the youth slang functioning are the following:

1. An attempt to make his/her speech incomprehensible to others.

2. The desire to express their emotions briefly but expressively (many slang words cannot be translated into literary language with one word, including translation into a foreign language).

3. The need to adapt to the social environment, to show that they belong to the company.

4. The desire to show their individuality, to be different from others.

5. An attempt to impress older people.

I. S. Alekseeva pointed out that when interpreting slang in another language, only those words that "have systemic lexical and grammatical correspondences to the target language" are subject to translation, and until recently, deviations from the literary norm of the language were not translated [5].

\subsection{Methods of youth slang formation}

Among the ways of the slang word-formation are the following:

- adaptation from other languages (primarily English);

- full and partial calquing (calque/semi-calque);

- translation (using standard vocabulary with a special meaning; using slang of other professional groups);

- phonetic mimicry;

- words in a figurative sense (metaphorization).

Currently, words adopted from other languages are the most numerous group of slang words.

When the adopted word penetrates into the Russian language, it is subjected to the inflection laws of the Russian language: askat' (ask, beg) - aski, laiknut (like) laikni, shoping (shopping) - zanimat'sya shopingom, shopagolic, frend (friend) - zafrenditsâ, etc. In addition, cognate word - derivatives are formed: kreza (madness) - crazy house, krezovnik, krezanuty (abnormal). In addition, cognate word - derivatives are formed: kreza (madness) - crazy house, krezovnik, krezanuty (abnormal). As it can be seen from the examples, adopted words are related to the fashion for imported goods, the development of social networks and computer technologies, the influence of youth club and music culture and the flexibility of slang words themselves.

Let us consider the ways of slang words formation: 1. Calquing (full calquing/semi-calquing). When calquing the word is adopted entirely, keeping its pronunciation, spelling and meaning. Calquing corresponds to all the norms of the language, although at first glance these words seem foreign in pronunciation and writing. When semi-calquing, the word is adopted from another language, taking on the phonetic and grammatical norms of the Russian language. Ring (phone) - ringat', ringanut (call), ringushnik (notebook with phone numbers).

2. Translation. Slang can be formed by the professional translation of the terms. The word can be translated using neutral variants, which acquire a new meaning with a reduced stylistic nuance: virus - living creatures. 
The second group is the terms translated using the vocabulary of other professional groups. As a result, the meaning of the word slightly changes acquiring a computer-specific slang meaning. The most common words and expressions of youth slang: incorrect programme - glucalo.

3. Metaphorization. A metaphor can be defined as "a word that replaces another word due to similarity or analogy between what they mean." [6]. Arising analogies or metaphors can be very diverse: the similarity of the object or device shape: disk - pancake (blin); adapter card - tile (plitka), to delete - demolish (snosit').

4. Phonetic mimicry. This method is based on the coincidence of semantically dissimilar common words and professional terms: error - Egor; button - baton, email - mylo, Emelya [7].

Thus, we can conclude that modern youth slang is a dynamic element of the language, which is constantly updated due to the adopted words from other languages. The vocabulary of any language is a system where each element has certain properties and occupies a certain place in it. Thus, youth slang forms a set of lexicalsemantic and thematic fields that combine common lexical meaning and relevance to a specific thematic group. I. V. Arnold pointed out that the term "slang word" was not quite accurate, because together with individual slang words there were lexical and semantic variants of words that combine "other, not slang variants" [4].

\section{Research results and discussion}

\subsection{Thematic groups of slang words}

As a result of the analysis the following thematic groups of slang words were identified:

1) names of human body parts (56/58 units);

2) various everyday situations (78/54 units);

3) university studies (33/24 units);

4) personal qualities (67/30 units);

5) attitude to the current events (41/52 units);

6) computers, Internet (58/65 units);

7) communication with age-mates (24/36 units).

The examples in the article are taken from everyday communication of young people (Russian slang). Besides, the interactive dictionary of youth slang (Russian and English slang) [8], which is freely available on the Internet, as well as "English-Russian and RussianEnglish dictionary of slang" [9] and "Dictionary of slang widely used among informal youth associations" [10] were used for the comparative analysis of Russian and English slang words.

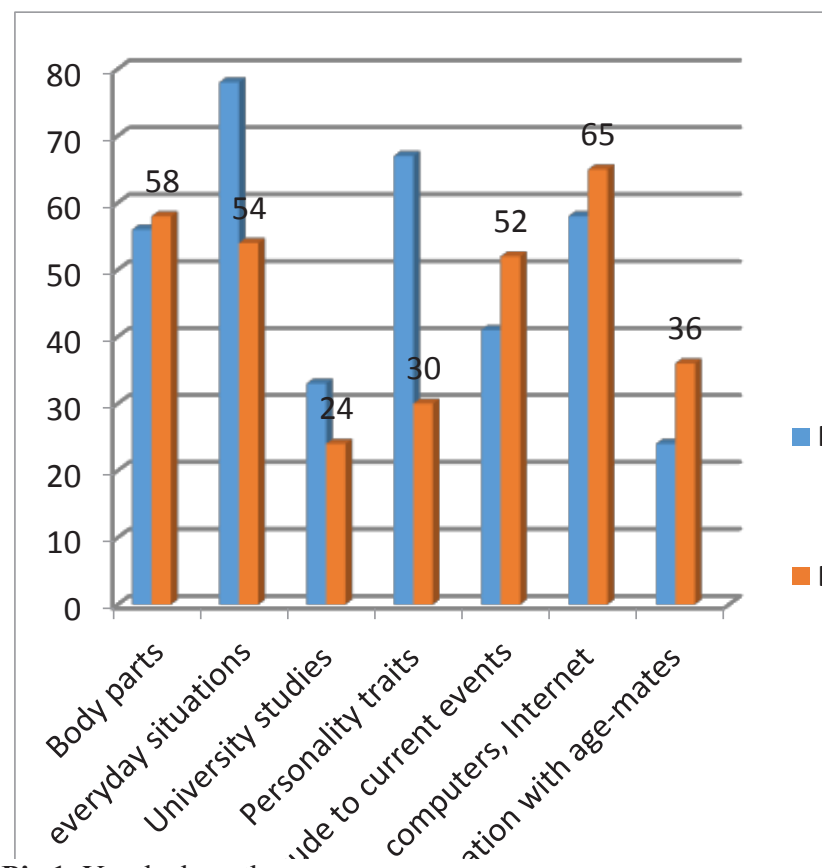

Pic 1. Youth slang theme groups

As it can be seen from Table 1 in the Russian language the most numerous slang groups are: "various everyday situations", "personal qualities of a person", "computers, the Internet", while in English the most numerous topics are "computers, the Internet" and "parts of the human body".

The group "communication with age-mates" turned out to be the smallest in Russian, and in English the smallest one was "University studies".

\subsection{Slang words denoting names of human body parts}

As a result of the study, 43 Russian units and 27 English units were allocated for this thematic group. During the analysis of this lexical units segment, the following subgroups were identified:
1) mouth $(11 / 12)$
2) face $(8 / 5)$
3) head $(8 / 12)$
4) nose $(4 / 6)$
5) hands $(8 / 5)$
6) eyes $(6 / 5)$
7) legs $(7 / 11)$
8) hair (2/ 5) 


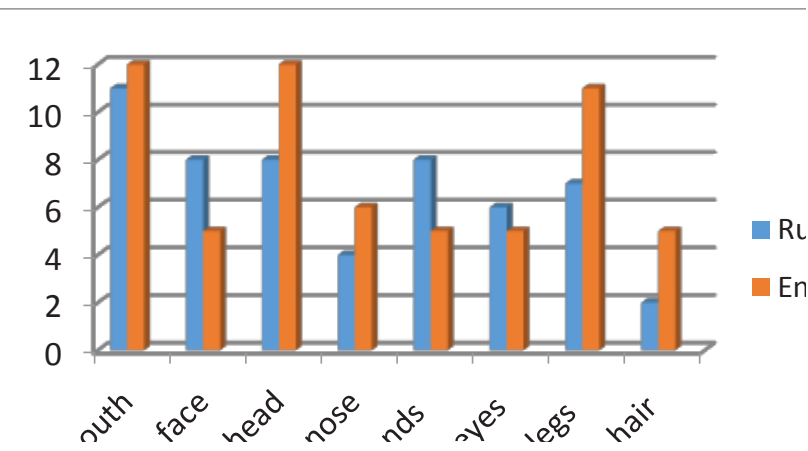

Pic 2.. Slang words relating to the names of parts of the human body

So, as it can be seen in Table 2, the largest subgroup of the Russian slang words is "mouth" and the smallest one is "hair".

The largest subgroup of the English slang words is "mouth", for example «mugg; jap; box; clam: gab; pie hole; talk trap» and others; and «head», for example «block; tomato; top storey; crown; knowledge-box» etc.; the smallest one is «eyes», for example, «lamp; glim; peek».

Slang words allocated in the thematic group "parts of the human body" are quite numerous in both languages. The majority of the slang words from this group have an explicit negative, dismissive, or ironic connotation. Using these slang words in the speech, young people will probably express a dismissive attitude to the surrounding reality. The main way to form these slang words is metaphorization, i.e. words are formed on the basis of associative links with a particular subject. All lexical units of this thematic group are nouns which make up a group of semantic synonyms.

\subsection{Slang words for different domestic situations}

As a result of the study on this thematic group, 76 lexical units were allocated in Russian and 52 ones in English. The following lexical subgroups were identified during the analysis:

1) names of the currency $(21 / 16)$;

2) names of persons by sex (28/26);

3) household slang (14/12);

4) things and their purpose (17/7).

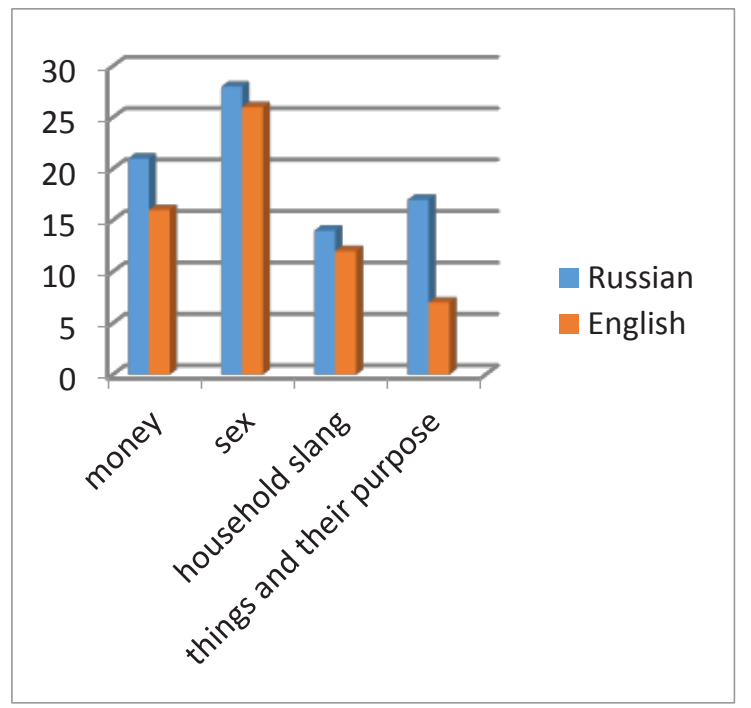

Pic 3 Slang words for different everyday situations

As it can be seen in Table 3, the largest number of slang words, both in Russian and in English, is represented by a synonymous group "name of persons by gender", and the smallest one by "household slang" in Russian, and "things and their purpose" in English.

Slang words for various everyday objects and situations are in most cases adopted from the English language or phonetic associations. The translation is much less frequent. For example, "bucks, gerla, man" - in Russian, "bucks, babe, mate, pal" - in English.

The use of slang words in various everyday situations is associated with the desire of most young people to express themselves by means of emotionally marked words, and sometimes with attempts to hide from others certain concepts and phenomena with the help of encrypted slang words known only to their social circle. The authors analyzed the most common slang words of the English language related to various everyday situations. About 30 words and expressions were highlighted. In our opinion, these are the words and expressions that can be used in foreign language classes for active learning by students, for example: "«wicked; bottom line; dig; all right?; pear shaped; cheers; chin wag; wind up; not my cup of tea; throw a spanner in the works»", etc.

\subsection{Slang words relating to the personal qualities of a person (56/336)}

1) words characterizing the personality traits $(21 / 65)$;

2) words describing the human mental abilities (18/77);

3 ) words of physical characteristics of a person (9/89);

4) words expressing attitudes towards women (5/81);

5 ) words describing the height of a person (3/24). 


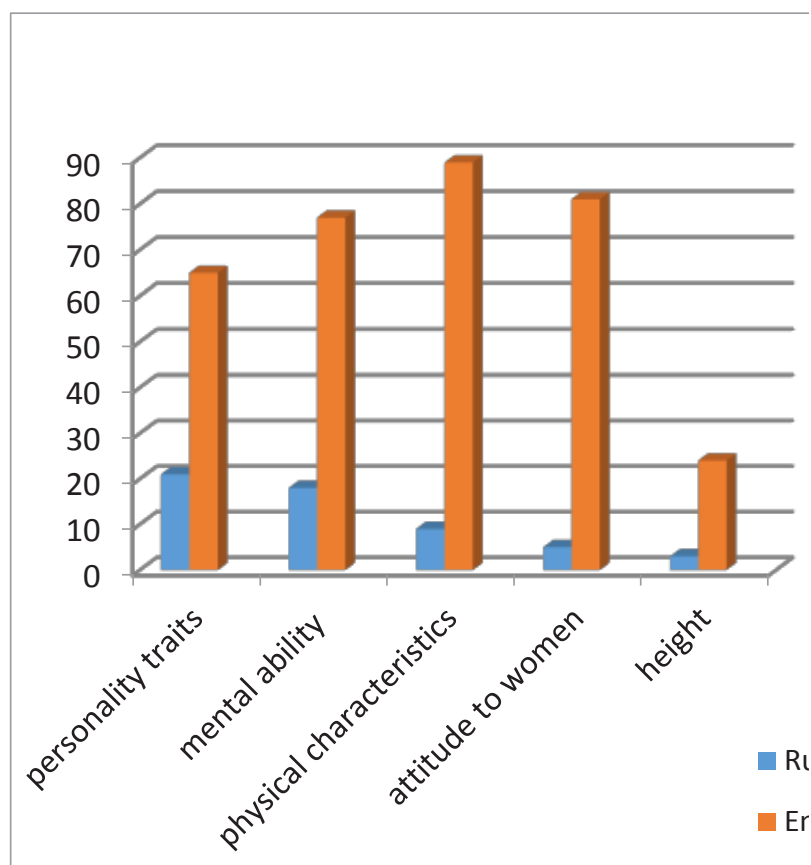

Pic 4. Slang words relating to the personal qualities of a person

Thus, slang words, used to determine the personal qualities of a person, constitute an extensive vocabulary segment in both Russian and English languages. In most cases, such words, highlighting any special quality having a negative connotation, are offensive and humiliating. In colloquial speech, alongside with slang words, colloquial words are used to create the effect of ease. Some lexical units of the Russian language correspond to lexical-semantic groups in the English language. For example, "shas (in a tick)", "po barabanu (I don't give a monkey's)", etc.

\section{Conclusion}

During the lexical-semantic analysis of 352 Russian and 649 English words, 7 thematic groups of slang words were identified. Thus, the research has shown that the following groups of slang words are the most numerous in the Russian language: "various everyday situations", "personal qualities of a person", "computers, Internet", whereas in English the groups "computers, Internet" and "parts of the human body" are the most common.

The most limited thematic group in Russian was the group "communication with age - teens", and in English - "University studies". Most of the lexical units belonging to the thematic group "parts of the human body" have a strongly pronounced negative connotation in both languages. Most likely, this is due to the desire of young people to express a real decline in negative attitudes towards the real world. In the Russian language, slang words with the meaning of "part of the human body" in most cases are not adopted, but have arisen on the basis of metaphor or association with a particular subject.

Lexical units, which denote the names of persons by their gender, have both negative and positive connotations in both languages. Most Russian and
English slang words are the result of metaphorization, except a few Russian words adopted from the English language.

Lexical units used to determine the physical and inner characteristics of a person constitute a large enough segment of vocabulary. As a rule, these slang words in most cases have a negative connotation and express the disdainful attitude of the speaker to others.

Words characterizing the name of monetary units in both Russian and English have neutral meaning.

Based on the lexical-semantic analysis of the features of youth slang, it can be concluded that slang performs an expressive function in the language, making it more emotional and expressive. The wide use of slang words testifies to the dynamic development of this segment of vocabulary in the modern Russian and English languages.

Thus, studying slang in foreign language classes can be of great interest for both teachers and students. If students are motivated enough to learn a foreign language, communicate with native speakers personally or in social networks, then studying some of the most common slang words and idiomatic expressions is definitely necessary. In our opinion, to start teaching slang in foreign language classes is advisable in a preIntermediate level group. Thus, in the Industrial University of Tyumen slang, idiomatic expressions and phrasal verbs are taught in groups of students of supplementary qualification "Translator in the field of professional communication."

\section{References}

1. V. Khomyakov non-Standard vocabulary in the structure of the English language of the national period. Abstract. doctor. Dis. ... kand. Philo. sciences'. L., (1980).

2. N. Beregovskaya Youth slang: formation and functioning. Questions of linguistics. 46-52 (1996)

3. D. Smirnov Youth slang from Stalin to the present day Komsomolskaya Pravda, 21, (04.09.2008)

4. I. Arnold Stylistics of modern English. 116 (M.: Enlightenment, 1990).

5. I. Alekseeva Introduction to translation studies. 203 (6th edition. M.: ACADEMIA, 2012).

\section{M. Black Metaphor. - Metaphor theory. 186 (1990)}

7. E. Matyushenko, Borrowing as one of the most productive ways of formation of units of modern youth slang Social variants of the language - II: materials international science. Conf. 386 - 389 (2003).

8. The online slang dictionary (American, English and Urban slang)

9. Alexey Kalinin: English-Russian and Russian-English slang dictionary. 226, (Publisher: M: Living language, 2016).

10. A. Mazurova Dictionary of slang common among informal youth associations Psychological problems of studying informal youth associations. (2004). 